OPEN ACCESS

Edited by:

Xiaodan Su,

Nanjing University of Posts and Telecommunications, China

Reviewed by:

Caroline Aquino Moreira-Nunes,

Federal University of Ceara, Brazil

Junhua Mai,

Houston Methodist Research Institute,

United States

${ }^{*}$ Correspondence:

Feng Chen

fengxiao6556@126.com

Feng Gao

rggaofeng@sdu.edu.cn

Guijie Li

sdulgj@163.com

Specialty section:

This article was submitted to Pharmacology of Anti-Cancer Drugs,

a section of the journal

Frontiers in Oncology

Received: 30 January 2021

Accepted: 06 May 2021

Published: 09 June 2021

Citation:

Liu Q, Zhao S, Meng F, Wang $H$,

Sun L, Li G, Gao F and Chen F

(2021) Nrf2 Down-Regulation

by Camptothecin Favors Inhibiting

Invasion, Metastasis and Angiogenesis

in Hepatocellular Carcinoma.

Front. Oncol. 11:661157.

doi: 10.3389/fonc.2021.661157

\section{Nrf2 Down-Regulation by Camptothecin Favors Inhibiting Invasion, Metastasis and Angiogenesis in Hepatocellular Carcinoma}

\author{
Qian Liu ${ }^{1,2}$, Shanshan Zhao ${ }^{3}$, Fanguang Meng ${ }^{1,2}$, Hankang Wang ${ }^{1,2}$, Liwei Sun ${ }^{1,2}$, \\ Guijie $\mathrm{Li}^{1 *}$, Feng $\mathrm{GaO}^{3 *}$ and Feng Chen ${ }^{1 *}$ \\ ${ }^{1}$ Department of Radiology, The First Affiliated Hospital of Shandong First Medical University \& Shandong Provincial \\ Qianfoshan Hospital, Jinan, China, 2 Shandong First Medical University \& Shandong Academy of Medical Sciences, \\ Jinan, China, ${ }^{3}$ Key Laboratory for Experimental Teratology of the Ministry of Education and Biomedical Isotope Research \\ Center, School of Basic Medical Sciences, Shandong University, Jinan, China
}

Higher oxidant stress capacity could promote invasion and metastasis. A previous study showed hepatocellular carcinoma (HCC) expressed more Nrf2 than para-carcinoma tissue. The chemotherapeutics such as epirubicin (EPI) could increase Nrf2 expression, while Camptothecin (CPT) could inhibit tumor growth by down-regulating the key molecule of antioxidant stress signal-Nrf2. The role of Nrf2 in invasion and metastasis was still unclear. In this study, we use EPI and CPT to determine the invasion and metastasis in Huh7 cells, H22 and Huh7 mouse models. In Huh7 cells, Nrf2 expression and ROS level were found increased after incubation with EPI by western blot and flow cytometry assay. But with the combination of EPI and CPT, inhibition of Nrf2 could decrease proliferation, invasion, and metastasis, which were investigated by CCK8 assay, wound healing, and Transwell assays. In Huh7 and H22 mouse models, EPI promoted Nrf2 up-regulation and nucleus translocation. Tumor growth was obviously inhibited with a single application of EPI or CPT. The combination of EPI and CPT could inhibit Nrf2 expression but demonstrated more suppressing effect of tumor growth than EPI. Western blot and immunohistochemical staining study revealed that Nrf2 inhibition was beneficial in decreasing the expression of N-cadherin, MMP9, Snail as well as Twist, and increasing Ecadherin, which were associated with epithelial-mesenchymal transition (EMT). Nrf2 down-regulation promoted lung metastasis of $\mathrm{H} 22$ cells in vivo. In addition, H\&E staining and immunofluorescence staining of VEGFR suggested angiogenesis of Huh7 and H22 tumors was reduced. In conclusion, down-regulation of Nrf2 demonstrated inhibition of invasion, metastasis, and angiogenesis of hepatoma, which may provide a potential therapy in HCC.

Keywords: hepatocellular carcinoma, metastasis, reactive oxygen species, Nrf2, camptothecin 


\section{INTRODUCTION}

Hepatocellular carcinoma (HCC) is the most common primary liver cancer and the fifth most common malignant cancer in the world $(1,2)$. Patients with HCC usually undergo intrahepatic or extrahepatic recurrence, accounting for about $90 \%$ of HCC related deaths $(3,4)$. Recently, oxidative stress, which elevated reactive oxygen species (ROS) production and promoted DNA damage and protein expression change, has been proved to be the main reason of the HCC development (5).

To maintain oxidative homeostasis, the tumor cells would activate nuclear factor E2-related factor 2 (Nrf2), the principal antioxidant response transcription factor. The Nrf2 pathway was the major regulator of antioxidant and cytoprotecting pathway (6). Under physiological conditions, Nrf2 is usually kept at the basal level in the cytoplasm and combined with Kelch-like ECHassociated protein 1 (Keap1) (7). Under oxidative stress, Nrf2 was detached from Keap1 after sensing the increase of ROS and then translocated to the nucleus, where Nrf2 dimerized with small MAF (sMAF) proteins, leading to a variety of downstream changes on anti-oxidant gene expression, such as NQO-1 and HO-1 (8-12).

Growing evidences suggested that over-expression of Nrf2 played an important role in the malignant cells' migration, which was the major contributor to the mortality of cancer patients (13-15). Cancer cells utilized the epithelial-mesenchymal transition (EMT) program to execute the invasion and metastatic cascade (16). The undergoing of EMT process was demonstrated by down-regulating the expression of E-cadherin (the epithelial marker) and N-cadherin (the mesenchymal marker), following the increased expression of Snail and Twist (core EMT programs' transcription factors) $(17,18)$. Meanwhile, the matrix metalloproteinase 9 (MMP9) contributed to invasion and metastasis through EMT in HCC (19). In the stage of tumor development, Nrf2 could promote the EMT by down-regulation of E-cadherin expression (20).

Angiogenesis was vital to tumor growth as it supplied the oxygen and nutrients (21). The ROS level affected the vasculature in a dose-dependent manner. Therefore, activated Nrf2 pathway could enhance angiogenesis via regulating the HIF-1 $\alpha$ /VEGF axis $(22,23)$. Knockdown of Nrf2 resulted in a decrease of vascular endothelial growth factor (VEGF), the growth factor with important pro-angiogenic activity (24). Down-regulation of VEGF inhibited blood vessel formation and subsequently slowed down the tumor growth (25).

These evidences indicated that the activation of Nrf2 may be positively correlated with the invasion, metastasis, and angiogenesis of HCC. In our previous study, we demonstrated that the inhibition of Nrf2 by Camptothecin (CPT) suppressed the proliferation of HepG2 and SMMC-7721 cells by enhancing the cytotoxicity of chemotherapeutic drugs in HCC cells (26). Here, we would demonstrate the effect of Nrf2 downregulation on invasion, metastasis, and angiogenesis of HCC in vivo and in vitro by single administration of epirubicin (EPI, a common chemotherapeutic drug) and combined administration of EPI and CPT, aiming to provide a novel strategy for HCC treatment.

\section{MATERIALS AND METHODS}

\section{Chemicals, Reagents, and Equipment}

The ROS kit was purchased from Beyotime (Shanghai, China). Nrf2 antibody and MMP9 antibody were obtained from Proteintech (Wuhan, China). The E-cadherin, N-cadherin, Snail and VEGFR antibody were obtained from Cell Signaling Technology (MA, USA). The Twist antibody, $\beta$-Tubulin and $\beta$ actin antibodies were obtained from Bioworld (Illinois, USA). DMEM medium (High Glucose), RPMI 1640 medium, and fetal bovine serum (FBS) were provided by Biological Industries (Kibbutz Beit Haemek, Israel). Penicillin (100 U/ml) and streptomycin $(100 \mu \mathrm{g} / \mathrm{ml}), 0.25 \%$ Trypsin Digestion solutions (without EDTA and phenol red), puromycin, and PIPA buffer kit with PMSF were obtained from Solarbio (China, Beijing). GLUTAMAX and Sodium Pyruvate were purchased from Gibco (South Australia, Australia). PBS buffer, TBST buffer, Crystal violet staining solution, $H \& E$ staining and immunofluorescence (IF) staining reagents were received from Servicebio (Wuhan, China). SDS-PAGE Gel Preparation Kit, protein maker, HRP-labeled Goat Anti-Rat IgG were provided by EpiZyme (Shanghai, China). ECL substrate was obtained from Merck Millipore (Darmstadt, Germany). CCK8 kit was provided by DOJINDO (Kumamoto Ken, Japan). Twenty four-well Transwell units and Matrigel were purchased from Coring Life Science (MA, USA). The epirubicin (EPI) and Camptothecin (CPT) were obtained from Selleck (Shanghai, China). The flow cytometry was performed in the CytoFlex counter of Beckman Company (CA, USA). The membrane of western blot was scanned by Tanon 4600 (Shanghai, China).

\section{Cell Culture}

Huh7 (Human Hepatocellular carcinoma cell lines) cells were obtained from the China National collection of Authenticated Cell Cultures. H22 (Murine Hepatocellular carcinoma cell lines) cell lines were obtained from Shanghai Zhong Qiao Xin Zhou Biotechnology. The Huh7 and $\mathrm{H} 22$ cells were cultured in $37^{\circ} \mathrm{C}$ and $5 \% \mathrm{CO}_{2}$. Huh7 cells were cultured in the DMEM medium (High Glucose) containing 10\% fetal bovine serum (FBS), 1\% GLUTAMAX, 1\% Sodium Pyruvate, and 1\% $100 \mathrm{U} / \mathrm{ml}$ penicillin, and $100 \mu \mathrm{g} / \mathrm{ml}$ streptomycin. H22 cells were cultured in the RPMI 1640 medium with $10 \%$ FBS, and $1 \% 100 \mathrm{U} / \mathrm{ml}$ penicillin and $100 \mu \mathrm{g} / \mathrm{ml}$ streptomycin.

\section{Generation of Nrf2 Knockdown Huh7 Cells}

Huh7 cells $\left(4 \times 10^{4} / 500 \mu \mathrm{l}\right)$ were seeded in 24 -well plates and incubated at $37^{\circ} \mathrm{C}$ and $5 \% \mathrm{CO}_{2}$, overnight. The HitransG A $(20 \mu \mathrm{l})$ was added into the well for $12 \mathrm{~h}$. Then, $10 \mu \mathrm{l} \mathrm{Scramble}$ negative control virus (sc RNAi) or lentivirus-shRNA Nrf2 virus $(\mathrm{Nrf} 2-\mathrm{KD})(\mathrm{MOI}=20)$ was added into the well. After $16 \mathrm{~h}$, the medium was removed, and the cells were covered with $2 \mathrm{ml}$ DMEM complete medium for $48 \mathrm{~h}$. Next, $2 \mathrm{ml}$ DMEM complete medium with puromycin $(4 \mu \mathrm{g} / \mathrm{ml})$ was added into the well for $48 \mathrm{~h}$. The transfection efficiency was observed in fluorescence microscope. The negative control virus or lentivirus-shRNA Nrf2 virus was purchased from Genechem (Shanghai, China). The targeted sequence was caGAGAAAGAATTGCCTGTAA. 


\section{RT-PCR}

Huh 7 cells $\left(1 \times 10^{6}\right)$ were collected to the Ep tube, and the mRNA was extracted by TRIzol method. Briefly, $1 \mathrm{ml}$ TRIzol was added to lyse the cells. Then $200 \mu \mathrm{l}$ chloroform was added into the Ep tube and centrifuged. The upper transparent liquid was collected to the new tube and mixed with equal isopropanol. The tube was centrifuged, and the supernatant was discarded. Then $1 \mathrm{ml} \mathrm{80 \%} \mathrm{ethanol} \mathrm{(dissolved} \mathrm{in} \mathrm{DEPC} \mathrm{water)} \mathrm{was} \mathrm{added} \mathrm{into} \mathrm{the}$ tube. Next, the $80 \%$ ethanol was removed by centrifugation. The RNA was dissolved in $20 \mu \mathrm{l}$ RNase free water. The mRNA concentration was measured by spectrophotometer. Then, inverse transcription was performed according to the description in Evo M-MLV RT-PCR Kit (AgBio, Hunan, China). The PCR was performed according to the description in Accurate Taq PCR Kit (AgBio, Hunan, China). The agarose gel electrophoresis was used to detect the expression of Nrf2 and internal control (GAPDH). NFE2L2 Primer: Forward: 5' TCAGCGACGGAAAGAGTATGA-3', Reverse: 5' CCACTGGTTTCTGACTGGATGT-3'. GAPDH Primer: Forward: 5'-AAGGTGAAGGTCGGAGTCAAC-3', Reverse: 5'TGTAGACCATGTAGTTGAGGTCA.

\section{Animal Models}

All animal experiments were performed according to the ARRIVE guidelines approved by the Animal Care and Use Committee of Shandong First Medical University. Male athymic nude mice and male BALB/c mice (6 weeks old) were purchased from Vital River Laboratory Animal Technology (Beijing, China) and fed under Specific pathogen free condition with free access to water and standard food.

In subcutaneous xenotransplant tumor models, $1 \times 10^{6} / 200$ $\mu 1$ PBS of Huh7 cells and $\mathrm{H} 22$ cells was implanted subcutaneously into male nude mice and $\mathrm{BALB} / \mathrm{c}$ mice, respectively. When the volume of tumors was approximately $1.0-1.5 \mathrm{~mm}^{3}$, the mice were divided into four groups including the control group (PBS), the EPI group (EPI: $1 \mathrm{mg} / \mathrm{kg}$ ), the CPT (CPT: $3 \mathrm{mg} / \mathrm{kg}$ ) and combined groups (EPI combination with $\mathrm{CPT}$ injection). The mice models were administered with drugs through intraperitoneal injection every three days. The tumor volume was calculated on 0 day (first injection), 2, 4, 6, 8, 10 days with the equation: Tumor volume $\left(\mathrm{mm}^{3}\right)=\pi / 6 \times$ Length $\times$ $\mathrm{Width}^{2}$ (27). After 10 days post first injection, the tumors were isolated and weighted. The tumor volume and weight were analyzed by GraphPad Prism and used to represent the tumor growth.

In lung metastasis mice model, $1 \times 10^{6} / 200 \mu \mathrm{l}$ PBS of H22 cells was injected to BALB/c mice via tail vein. 6 days later, the mice group were divided into the control group, EPI group, CPT group, and combined group following the treatment of PBS, EPI $(1 \mathrm{mg} / \mathrm{kg})$, CPT $(3 \mathrm{mg} / \mathrm{kg})$, and combination of two drugs every three days. After 10 days of drug administration, the lungs of mice were separated and weighted.

\section{ROS Level Detection}

The Huh7 cells was adjusted to $1 \times 10^{6} /$ well in $2 \mathrm{ml}$ complete DMEM medium and placed in six-well plates overnight.
Cells were treated with $0.12 \mu \mathrm{M}$ EPI (dilution in sterility PBS buffer) and $0.5 \mu \mathrm{M}$ CPT (dilution in DMSO) for $48 \mathrm{~h}$. After removing the medium, $10 \mu \mathrm{M}$ DCFH-DA solution in serum-free DMEM medium $(1 \mathrm{ml})$ was added into the well and incubated for $20 \mathrm{~min}$. The cells were washed three times with serum-free DMEM medium to remove DCFH-DA. Then, cells were collected and resuspended in $0.5 \mathrm{ml}$ PBS for analysis by flow cytometry.

\section{Western Blot}

The tumors were smashed in the RIPA buffer with $1 \mathrm{mM}$ PMSF on ice. The cells were treated for $48 \mathrm{~h}$ and were lysed. Next, tissue and cells were centrifuged, and supernatants were treated with loading buffer. The samples were loaded into the SDS-PAGE gel, and electrophoresis of transmembrane was performed. The target membranes were covered with blocking buffer and then incubated with appropriate antibody overnight. Then, the membranes were incubated with HRP-labeled Goat AntiRabbit IgG solution and HRP-labeled Goat Anti-mouse IgG solution. Finally, membranes were covered with ECL substrate and scanned. The protein expression was represented by the gray assay of targeted membrane.

\section{Immunohistochemical Staining and Immunofluorescence Staining}

After 10 days post first injection, paraffin sections of tumors were deparaffinized and rehydrated. Then, the sections were incubated with EDTA antigen repair buffer ( $\mathrm{pH} 9.0$ ) to perform the antigen retrieval. Next, sections were blocked with BSA for $30 \mathrm{~min}$ and covered with appropriate antibody at $4^{\circ} \mathrm{C}$, overnight. Next, the sections were treated with different secondary antibodies in IHC staining and IF staining. In IHC staining, the sections were incubated with HRP-conjugated secondary antibody, and then were added with $\mathrm{DAB}$ substrate. The hematoxylin was used to perform the nucleus counterstaining. Finally, the cell nucleus was blue, and the positive expression of the targeted protein was brownish yellow. In IF staining, the sections were covered with Cy3(red)- or FITC (green)-conjugated secondary antibody. DAPI reagent (blue) was added to sections to indicate the cell nucleus. The positive expression of targeted protein was green or red. The assay of protein expression in the tissue was analyzed by Image Pro Plus and represented as IOD/Area value.

\section{Cell Proliferation}

The Huh7 cells were adjusted to 7,500 cells/100 $\mu$ l of complete DMEM medium and added into 96-well plates overnight. Then, EPI and CPT were dissolved in $100 \mu \mathrm{l}$ complete DMEM medium and treated to the cells. The final concentrations of EPI and CPT were $0.12 \mu \mathrm{M}$ and $0.5 \mu \mathrm{M}$, respectively. Cell counting kit- 8 (CCK-8) reagent $(5 \mu \mathrm{l})$ was added to the cell suspension and OD value in $490 \mathrm{~nm}$ was measured in a microplate reader. Experiments were repeated four times.

\section{H\&E Staining}

The tumor, lung, and liver on 10 days post first injection were prepared in paraffin sections, and then stained following the 
specification of $\mathrm{H} \& \mathrm{E}$ staining kit. Briefly, following deparaffinization and rehydration, hematoxylin was added to the sections for $5 \mathrm{~min}$. Then $1 \%$ acid ethanol reagent was covered on sections for $5 \mathrm{~s}$. Then, the blue returning liquid promoted the tissue to return blue, and then the eosin solution was incubated with sections for $10 \mathrm{~min}$. Finally, the sections were dehydrated and fixed with neutral balsam. The image was obtained under the optical microscope. The nuclear was blue, and cytoplasm was pink.

\section{Wound Healing Assays}

Cells $\left(1 \times 10^{6} /\right.$ well $)$ were added into six-well plates and cultured in complete DMEM medium overnight. Cells were scratched by a sterile pipette tip and washed with PBS for three times and cultured in DMEM medium without FBS. The cells were treated with $0.12 \mu \mathrm{M}$ EPI and $0.5 \mu \mathrm{M}$ CPT, respectively. The wounds were examined at 0,24 , and $48 \mathrm{~h}$ post scratch.

\section{Transwell Assay}

Transwell assays for migration were performed in Transwell inserts of 24 -wells with $8 \mu \mathrm{m}$ pore polycarbonate membrane. The upper compartments were added with Matrigel $(100 \mu \mathrm{l}$, $300 \mu \mathrm{g} / \mathrm{ml}$ ). Huh7 cells were suspended in serum-free DMEM at $2.5 \times 10^{4} / \mathrm{ml}$. Then, the inner chamber was added with $200 \mu \mathrm{l}$ cells, and the outer chamber was added with $750 \mu \mathrm{l}$ complete DMEM medium. After $48 \mathrm{~h}$, cells in the inner chamber were carefully removed. The migrating cells on the outside of the membrane were stained with Crystal violet solution buffer, following photographed under bright-field microscope $(400 \times$ magnification). Each experiment was performed in triplicate.

\section{Statistical Assay}

All experiments were performed at least three times and analyzed by GraphPad Prism. The data were expressed as mean $\pm \mathrm{SD}$, and one-way ANOVA with Tukey's multiple comparison tests was used for analysis in two-group datasets at a significance level of $\mathrm{P}<0.05$.

\section{RESULTS}

\section{CPT Down-Regulated ROS and Inhibited the Nrf2 Expression in HCC}

EPI and CPT were used to treat the HCC cells so as to investigate the effect of ROS level in HCC cells. In Figure 1A, we found the ROS level in the EPI group was higher than that in the control group $(\mathrm{P}<0.05)$. After treatment with $\mathrm{CPT}$, whether in the $\mathrm{CPT}$ group or the combined group, ROS level was significantly decreased compared with that in the control group (CPT group $v s$ control group, $\mathrm{P}<0.05$; combined group $v s$ control group, $\mathrm{P}<0.05$ ). More importantly, the ROS level was lower in the combined group than in the EPI group (combined group $v$ EPI group, $\mathrm{P}<0.05)$.

We generated the Nrf2 knockdown (Nrf2-KD) Huh7 cells, so as to analyze the effect of EPI and CPT on Nrf2 regulation in Huh7 cells. As shown in Figures 1B, C, we found Nrf2 expression was significantly decreased in the Nrf2-KD group compared with the scramble negative control group (sc RNAi) $(\mathrm{P}<0.05)$. Nrf2 expression was higher in the EPI group than that in the control group. Nrf2 expression was significantly inhibited in the CPT group compared with that in the control group $(\mathrm{P}<$ $0.05)$. Meanwhile, Nrf2-KD significantly inhibited the expression of downstream proteins (NQO-1, HO-1) of Nrf2 $(\mathrm{P}<0.05)$. In the EPI group, the expression of NQO-1 and HO-1 was higher than that in the control group $(\mathrm{P}<0.05)$. In the CPT and combined groups, the expression of NQO-1 and HO-1 was significantly decreased in comparison with that in the control group $(\mathrm{P}<0.05)$. Moreover, the combined group also showed
A
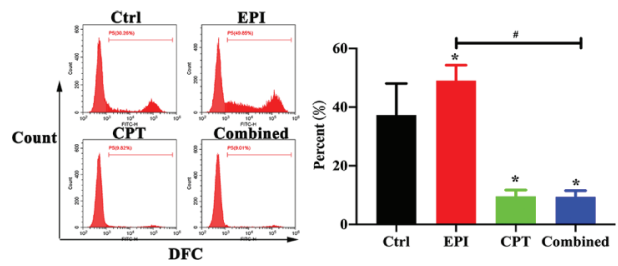

B

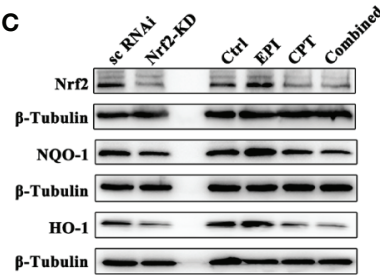


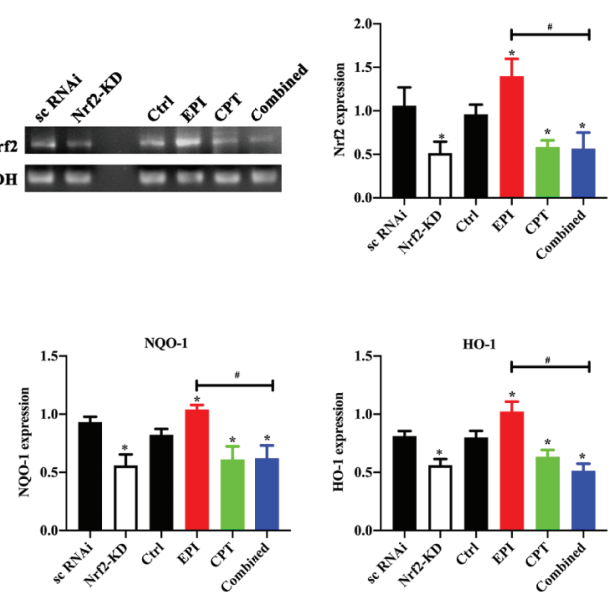

FIGURE 1 | Expression of ROS level and Nrf2 expression with EPI and CPT administration in Huh7 cells. The non-transfected Huh7 cells were treated with EPI and CPT for $48 \mathrm{~h}$. The sc RNAi and Nrf2-KD were transfected with scramble negative control and Nrf2-knockdown RNAi. (A) ROS level detected by flow cytometry after EPI and CPT intervention in Huh7 cells. (B) The mRNA expression and assay of Nrf2 by western blot in Huh7 cells. (C) The protein expression of Nrf2, NQO-1, and HO-1 in Huh7 cells. ${ }^{*} \mathrm{P}<0.05,{ }^{\#} \mathrm{P}<0.05$. 
lower NQO-1 and HO-1 expression than the EPI group. The level of Nrf2, NQO-1, and HO-1 in the CPT group and the combined group approximated that in the Nrf2-KD group. These results indicated the CPT inhibited the expression of Nrf2 and downstream protein (NQO-1 and HO-1) in Huh7 cells.

In order to detect the effect of EPI and CPT on Nrf2 regulation in vivo, western blot and IHC staining were performed in subcutaneous xenograft mouse models of Huh7 and H22 cells. In Figures 2A-C, we observed that treatment of CPT could downregulate the expression $\mathrm{Nrf} 2$ compared with the control group (CPT group vs control group, $\mathrm{P}<0.05)$. Although Nrf2 expression was obviously increased in the EPI group $(\mathrm{P}<0.05)$, the combined administration of CPT with EPI could decrease the Nrf2 expression compared with the control group $(\mathrm{P}<0.05)$ and the EPI group $(\mathrm{P}<$ 0.05). In the control group and CPT group, Nrf2 (red) was mainly distributed in the cytoplasm. Nrf2 translocated from the cytoplasm to the nucleus after EPI treatment, while Nrf2 translocation was found decreased after CPT treatment. These results indicated that CPT can inhibit Nrf2 nuclear translocation and affect its transcription function (Figure 2D).
A
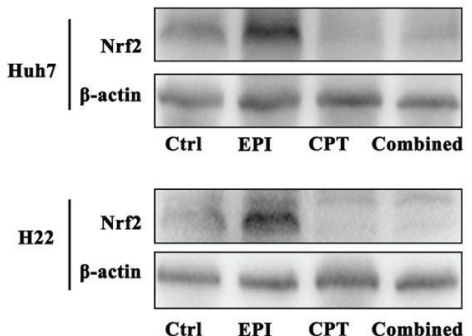
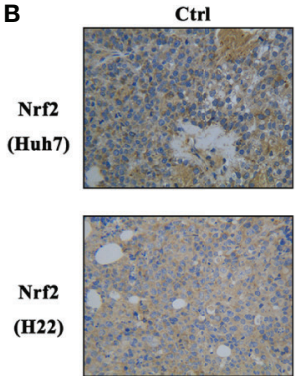

EPI
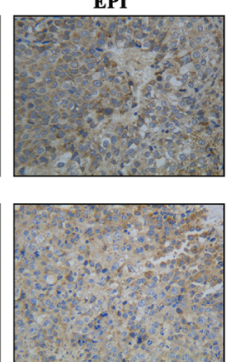

CPT


C
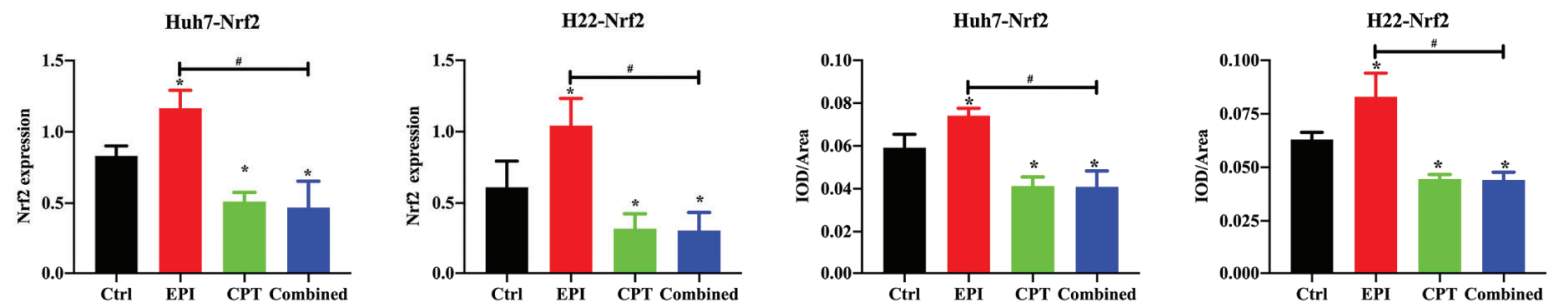

D

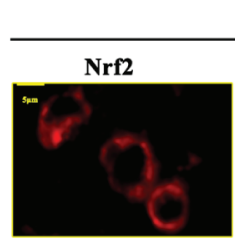

Huh 7

D


H22
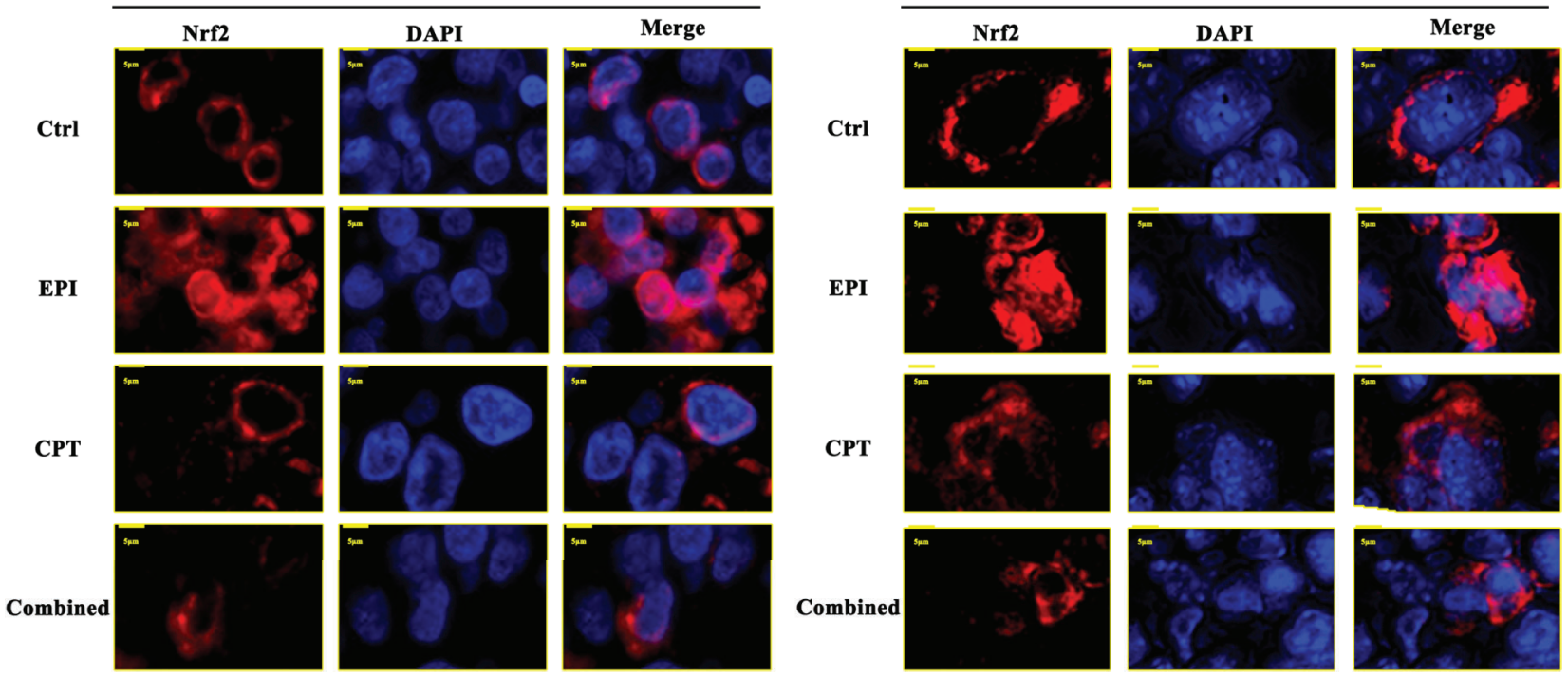

FIGURE 2 | Expression of Nrf2 expression and translocation with EPI and CPT administration in Huh7/H22 tumor cells. The subcutaneous tumors of Huh7 and H22 were separated on 10 days post first injection of EPI and CPT. (A) The Nrf2 expression by western blot. $\beta$-actin was the internal control. (B) The Nrf2 expression and assay by IHC staining. (C) The assay of Nrf2 expression. (D) The nucleus translocation of Nrf2 (red) in Huh7 and H22 tumors. DAPI (blue) indicated the nucleus. ${ }^{\star} \mathrm{P}<0.05,{ }^{\text {\# } \mathrm{P}}<0.05$. 


\section{CPT Suppressed HCC Cell Proliferation and Tumor Growth by Nrf2 Down-Regulation}

We investigated the effects of Nrf2 expression on the proliferation of Huh7 cells, as well as the tumor growth in subcutaneous xenograft Huh7 and H22 mice model. The results in Figure 3A suggested that the proliferation of Huh7 cells in the EPI, CPT, and combined groups was significantly lower than that in the control group at 24 and $48 \mathrm{~h}$ post drug treatment. The proliferation of Huh7 cells in the combined group was significantly slower than that in EPI group.

In Huh7 and $\mathrm{H} 22$ tumor bearing mice, the volume of tumors (Figures 3B, C) was measured on 2, 4, 6, 8, and 10 days and also weighed on day 10 (Figures 3D, E), after drug treatment. The smaller tumor size and lower tumor weight were found in the $\mathrm{EPI}, \mathrm{CPT}$, and combined groups than those in control group. Suppression of Nrf2 by CPT in the combined group remarkably decreased the tumor size and the tumor volume compared with EPI groups.

\section{CPT-Induced Nrf2 Suppression Contributed to Inhibiting EMT Process}

Molecular alterations of EMT progress after modulating Nrf2 expression were studied by IHC staining and western blot in Huh7 cells and Huh7/H22 tumor model treated with EPI and $\mathrm{CPT}$.

In Huh7 cell lines (Figure 4), the Nrf2 down-regulation by Nrf2 RNAi significantly increased the expression of E-cadherin and decreased the expression of N-cadherin, MMP9, Snail and Twist, and MMP9. In the Nrf2-KD group, the CPT group and combined group, the expression of E-cadherin was increased and the expression of N-cadherin, MMP9, Snail and Twist was decreased compared with the control group. EPI had a significant effect on EMT process. These results demonstrated that Nrf2 downregulation favored the inhibition of the EMT process.

In the Huh7/H22 tumor model (Figure 5), the expression of $\mathrm{N}$-cadherin, Snail, Twist, and MMP9 was significantly decreased after CPT administration (CPT group and combined group), compared with the control group. The combined group had less expression of $\mathrm{N}$-cadherin, Snail, Twist, and MMP9 than the EPI group. Expression of E-cadherin in the CPT and combined groups was higher than that in the control group. The western blot study further confirmed the finding in IHC staining.

\section{CPT Suppressed Invasion and Metastasis of HCC via Down-Regulation Nrf2}

The wound healing and Transwell assays with Huh7 cells in vitro and lung metastasis study in $\mathrm{H} 22$ mouse model were performed so as to investigate the effects of Nrf2 expression on invasion and metastasis in HCC.

In the Transwell assay (Figure 6A), the numbers of migrated cells in the EPI, CPT, and combined groups were much fewer than that in the control group at $48 \mathrm{~h}$ post drug administration. And, the combined group showed less cell migration than the EPI groups.

In wound healing assay (Figure 6B), the wound closure in EPI, CPT, and combined groups was much narrower than that in the control group at 24 and $48 \mathrm{~h}$. However, the wound closure

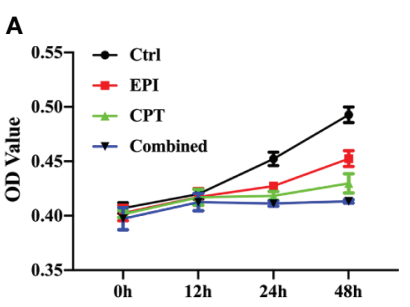

D
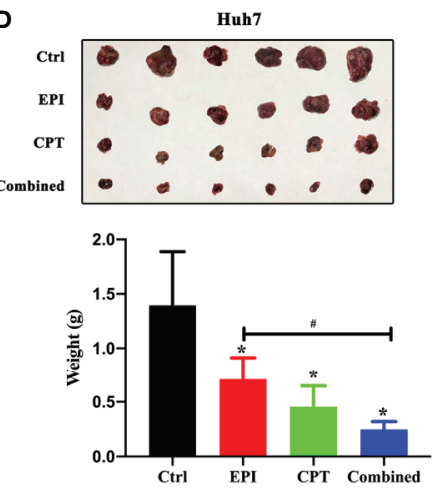
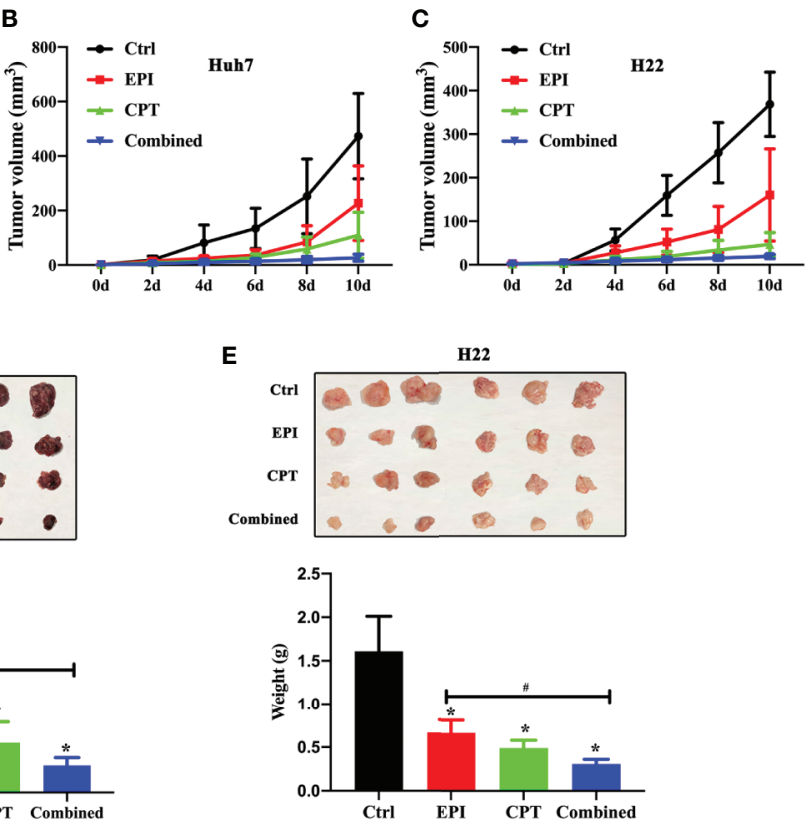

FIGURE 3 | Down-regulation Nrf2 by CPT suppressed proliferation of Huh7 cells and tumor growth of Huh7 and H22. (A) Proliferation of Huh7 cells was measured and presented as OD value at 0, 12, 24, and 48h. (B, C) Tumor volume of Huh7 cells (B) and H22 cells (C). (D, E) The tumor weight of Huh7 cells (D) and H22 cells (E). ${ }^{\star} \mathrm{P}<0.05,{ }^{\#} \mathrm{P}<0.05$ 

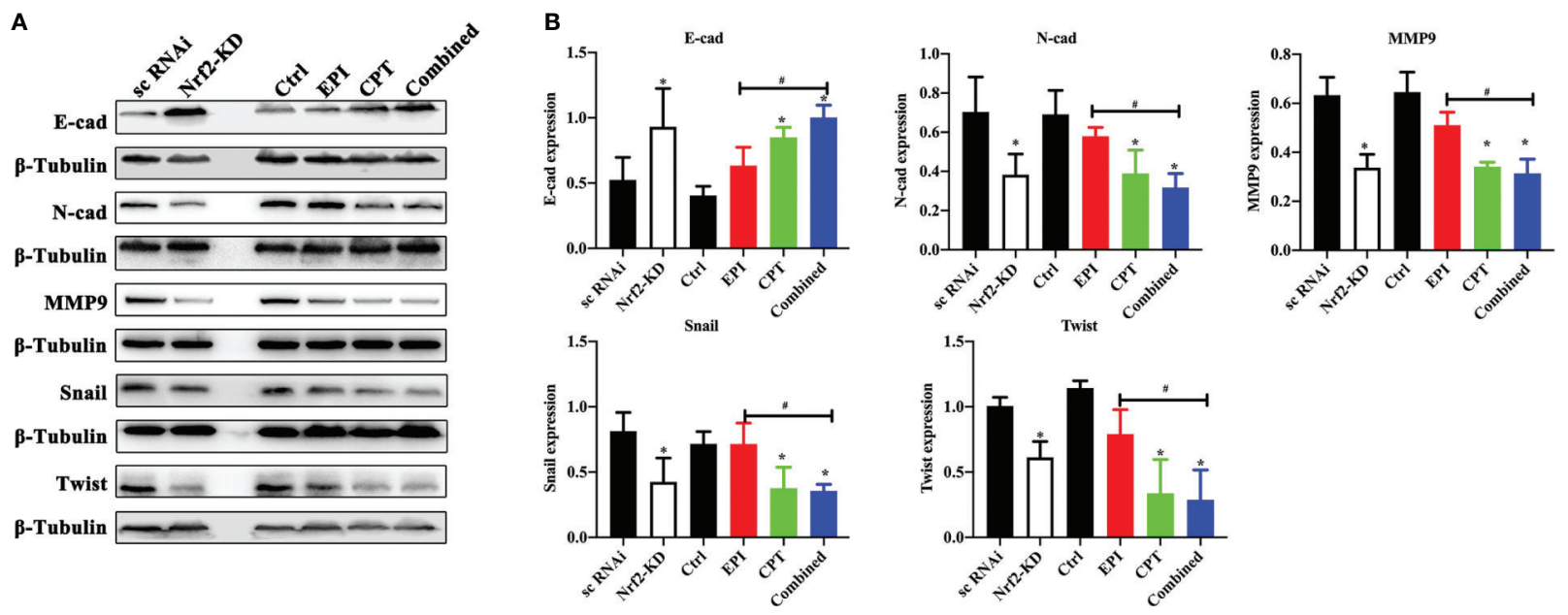

FIGURE 4 | CPT suppressed EMT progress of Huh7 cells. The non-transfected Huh7 cells were treated with EPI and CPT for 48 h. The sc RNAi and Nrf2-KD were transfected with scramble negative control and Nrf2-knockdown RNAi. (A) The expression of E-cadherin (E-cad), N-cadherin (N-cad), MMP9, Snail and Twist was measured by western blot. (B) Densitometry assay of the band in western blot. $\beta$-Tubulin was the internal reference. ${ }^{*} P<0.05$, ${ }^{\#} P<0.05$.

in the EPI group was wider than that in the combined group after Nrf2 down-regulation.

In lung metastasis assay, the lung was weighted on day 16 post injection of $\mathrm{H} 22$ cells. The $\mathrm{H} \& \mathrm{E}$ staining of the lung and liver was also performed. In Figure 6C, great amounts of macroscopic $\mathrm{H} 22$ cell nodules were visible in the lung tissue in the control group, and more infiltration of $\mathrm{H} 22$ cells were observed by $\mathrm{H} \& \mathrm{E}$ staining in Figure 6E. After treatment with EPI and CPT, the macroscopic H22 cells' nodules decreased, and lung weight was remarkably reduced (Figure 6E). Lung weight was found lighter in the combined group than that in the EPI group (Figure 6D). More interestingly, the $\mathrm{H} 22$ cells nodules were also found in liver tissues (Figure 6F). The size of tumor was smaller in the EPI, $\mathrm{CPT}$, and combined groups compared with that in the control group. Some parameters in the combined group, such as the amount of tumor nodules, lung weight, H22 cell infiltration, and the size of tumor metastasis in the liver, were much poorer than those in the EPI group.

\section{CPT Inhibited Angiogenesis of HCC via Down-Regulation Nrf2}

The expression of angiogenesis in tumor tissues was analyzed in Huh7 and H22 tumor bearing mice by H\&E and IF staining of VEGFR after treatment with EPI and CPT.

$\mathrm{H} \& \mathrm{E}$ staining of Huh7 and H22 tumors (Figure 7A) indicated that more vessels were found in the control group compared with the EPI group. Interestingly, vessels in the control group were thicker than that in the EPI group. After Nrf2 downregulation by $\mathrm{CPT}$ intervention, the number and the thickness of vessels were obviously reduced in comparison with the control group. Moreover, the combined group also exhibited fewer vessels than the EPI group, and the vessels in the combined group were found finer.

In addition, angiogenesis in the EPI group was less than that in the control group (Figure 7B). As Nrf2 was down-regulated by CPT administration, the combined group demonstrated lower VEGFR expression than the control group. Meanwhile, lower VEGFR expression was found in the combined group than that in the EPI group.

\section{DISCUSSION}

Cancer cells exhibit fast metabolism, which requires a high concentration of ROS to maintain their fast proliferation (28). High level of ROS could lead to nucleus genomic instability to accelerate the progress of the cancer development, including promoting cell proliferation, invasion, and metastasis by activating plenty of signal proteins (29-31). ROS in cancer cells could also be increased by different therapeutic strategies, such as chemotherapy, radiotherapy, and other methods $(32,33)$. In tumor chemotherapy, the chemotherapeutic drugs could enhance the killing efficiency of tumor via inducing intracellular ROS response. However, increased ROS level could also induce abnormal activation of $\mathrm{Nrf} 2$ and then promote the migration and metastasis of tumor $(19,34)$. Therefore, inhibiting the activation of Nrf2 pathway in the tumor was vital to inhibit the progression of tumor. A large number of studies have proved that Nrf2 stayed in lower activation state in normal tissues. In contrast, primary tumors and metastatic tumors showed high Nrf2 expression and Nrf2 activation $(22,23)$. Our previous study showed that HCC had more Nrf2 expression than para-carcinoma tissue, and the high expression of Nrf2 promoted the progress of HCC and its chemotherapy resistance (24). Therefore, targeting Nrf2 maybe provide a novel strategy to suppress the tumor progression.

As a common chemotherapeutic drug for HCC, EPI has the characteristics of general chemotherapeutic drugs (35). In the metabolic process, EPI could kill the tumor by inducing ROS accumulation, promoting the overload of intracellular calcium 
A

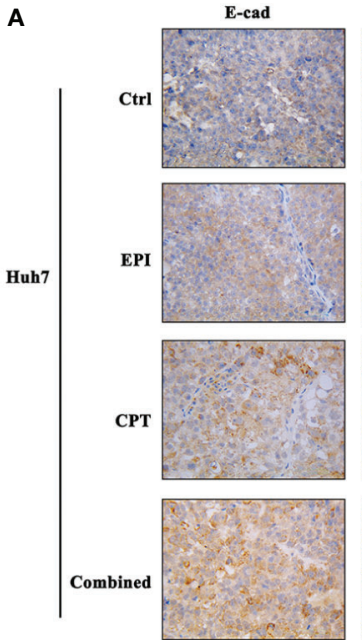

C

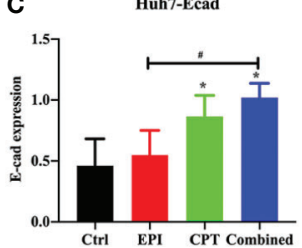

D
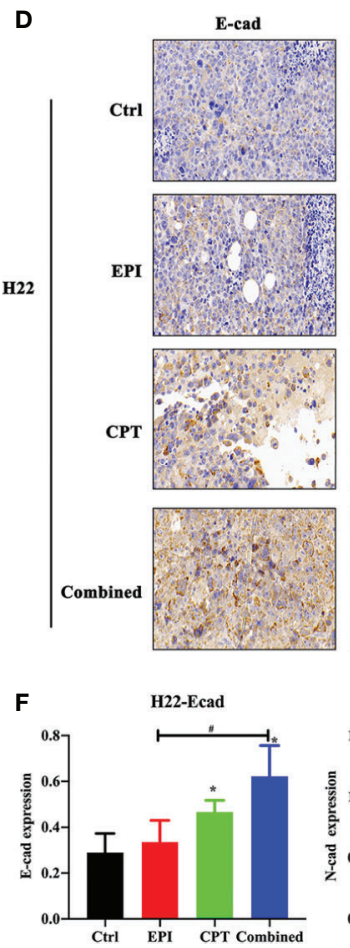

N-cad


Huh7-Nead
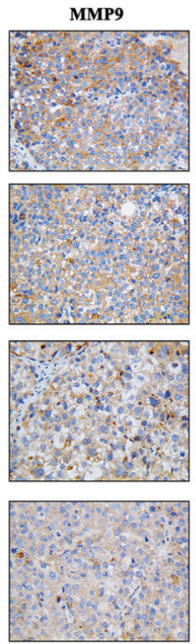

Snail

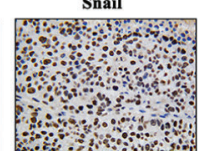

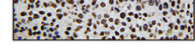
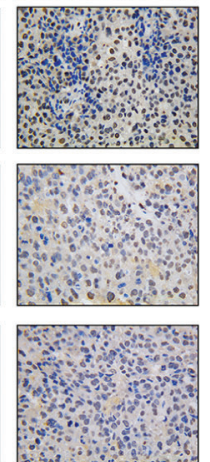

Huh7-MMP9

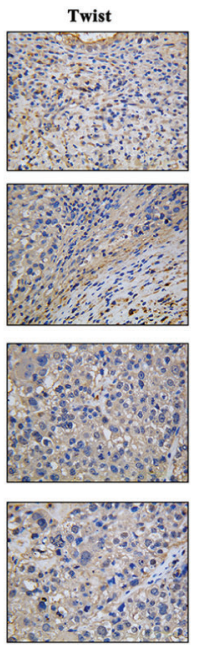

Huh7-Snail

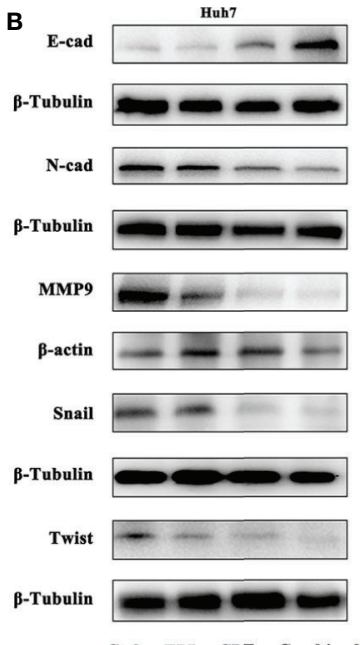

Ctrl EPI CPT Combined Huh7-Twist
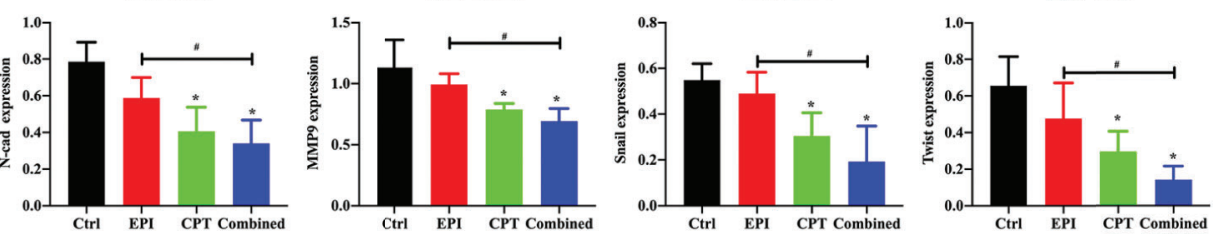

E
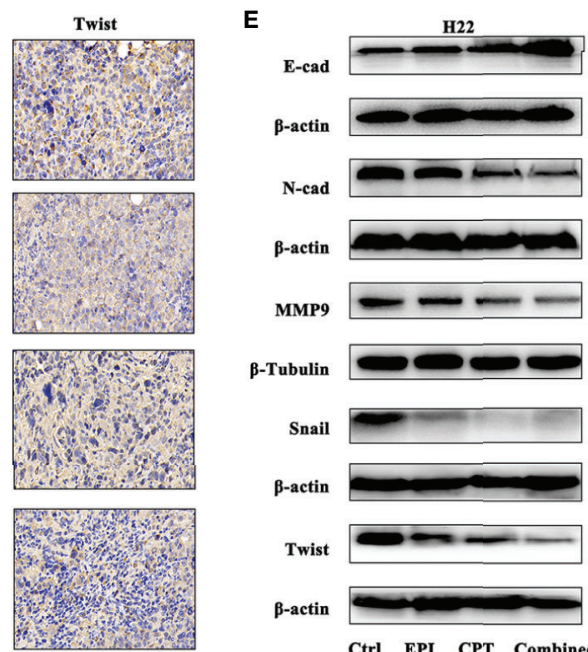

B-Tubulin

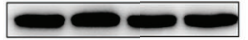

Sna

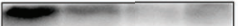

$\beta$-actin

Twist

$\beta$-actin

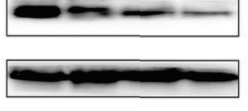

Ctrl EPI CPT Combined

H22-MMP9

H22-Snail

H22-Twist
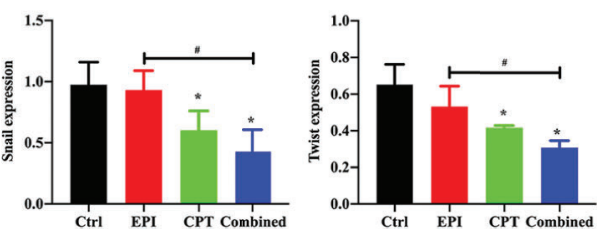

FIGURE 5 | CPT suppressed EMT progress of subcutaneous xenotransplanted Huh7 and H22 tumors. The EMT progress assay was performed by subcutaneous xenotransplanted Huh7 and H22 tumors. (A, B) The expression of E-cadherin (E-cad), N-cadherin (N-cad), MMP9, Snail and Twist was measured by immunohistochemical staining (A), and western blot (B) in Huh7 tumor. (C) Densitometry assay of the band in western blot in Huh7 tumor. (D-F) The expression of E-cadherin (E-cad), N-cadherin (N-cad), MMP9, Snail and Twist was measured by immunohistochemical staining (D), and western blot (E) in H22 tumor. (F) Densitometry assay of the band in western blot in $\mathrm{H} 22$ tumor. $\beta$-actin and $\beta$-Tubulin were the internal reference. ${ }^{*} \mathrm{P}<0.05$, ${ }^{\#} \mathrm{P}<0.05$. 
A



Ctrl

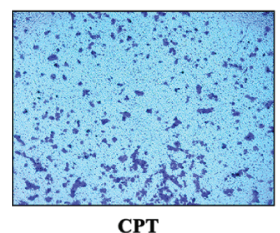

CPT

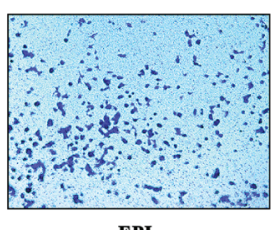

EPI

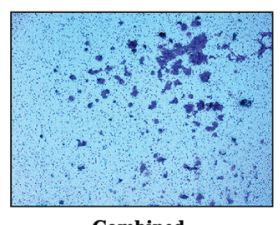

Combined

C

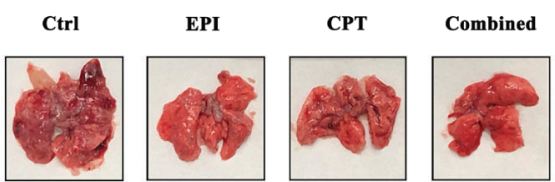

D

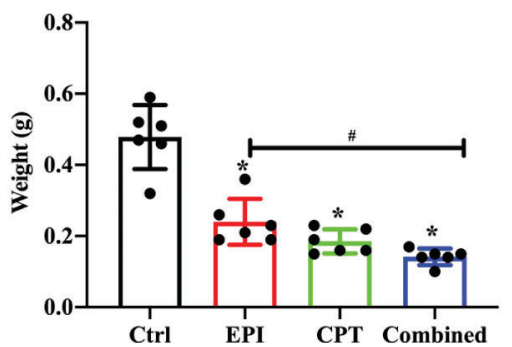

B

Oh
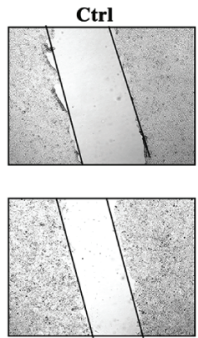

$48 \mathrm{~h}$


$\mathbf{F}$

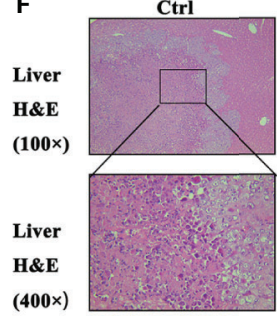

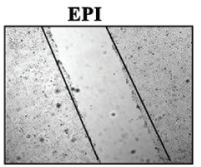
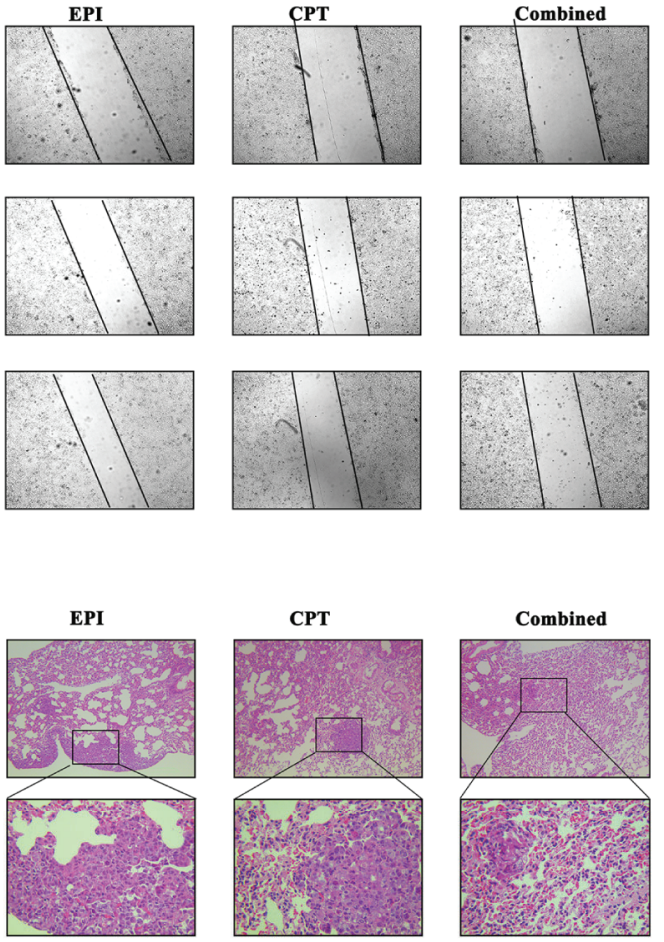

EPI


FIGURE 6 | The invasion and metastasis assay of HCC in vitro and in vivo. (A, B) The invasion and metastasis assay of Huh7 cells in vitro. (A) Transwell assay showed the migration of huh7 cells at $48 \mathrm{~h}$. (B) In wound healing assay, migration of Huh7 cells was examined at 0, 24 , and 48 h. (C-F) The invasion and metastasis assays of $\mathrm{H} 22$ cells in vivo was detected by lung metastasis assay 10 days after the first drug injection. (C) The image of lung in mice model. (D) The assay of lung weight in mice model. (E, $\mathbf{F})$ The H\&E staining of lung (E) and liver (F). ${ }^{*} P<0.05,{ }^{\#} \mathrm{P}<0.05$

and inducing apoptosis and necrosis of tumor $(29,30)$. However, the high ROS level induced by EPI may result in abnormal activation of Nrf2. Abnormal activation of $\mathrm{Nrf} 2$ enhanced tumor invasion and metastasis of tumor through cascade reaction of downstream proteins. Now, many evidences have confirmed that Nrf2 activation could inhibit the degradation of Bach1, and then promote the progress of lung cancer $(23,31)$.

$\mathrm{Nrf} 2$ was the main regulator against ROS response in cells, and it could control the antioxidant response elements (AREs) by interaction with small MAF proteins (36). Nrf2 was the central protein of the Kelch-like ECH-associated protein 1 (Keap1)Nrf2-ARE pathway (37). In the classical pathway, Keapl protein mediated the ubiquitination degradation of Nrf2 protein when ROS was in physiological level. However, when ROS was increased, Nrf2 which was no longer degraded by Keap1 could enter the nucleus to activate the downstream antioxidant genes $(38,39)$. Then Nrf2 translocated and regulated the antioxidant proteins to protect cells against oxidative stress via controlling the various oxidation resistance genes, such as glutamate cysteine ligase (GCL), glutathione reductase (GSR), SLC7A11 (40-42). In our previous study, we have screened out an effective Nrf2 inhibitor-camptothecin (CPT) - from thousands of clinical drugs by ARE luciferase reporter assay $(20,24)$. CPT could specifically inhibit the activity of Nrf2 without increasing the level of intracellular ROS (26). As a long-standing clinical chemotherapeutic drug, its safety has been fully confirmed (43, 44). Moreover, the dosage of $\mathrm{Nrf} 2$ inhibitor in our study (in vivo: $\mathrm{mg} / \mathrm{kg}$ ) was lower than that for chemotherapy in clinics $(8 \mathrm{mg} /$ $\mathrm{kg}$ ) (26). It was also proved that combination of CPT with EPI could effectively inhibit Nrf2 expression in HepG2 and SMMC7721 cells (26). Considering that tumor progression was mainly affected by tumor proliferation, invasion, metastasis, and the amount of angiogenesis, the Nrf2 inhibition by CPT may provide a novel exploration about invasion, metastasis, and angiogenesis 
A
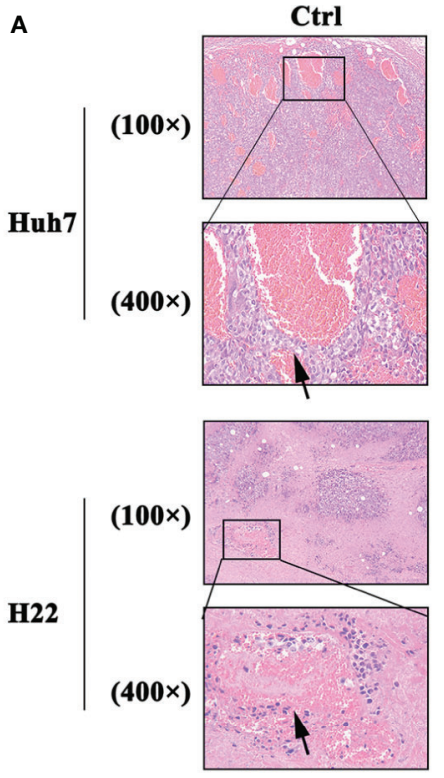

B

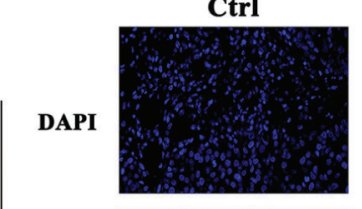

Huh7

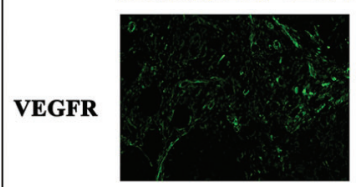

Merge

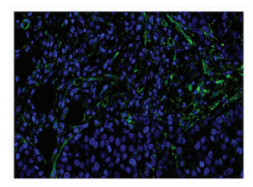

VEGFR


Merge

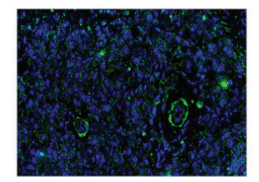

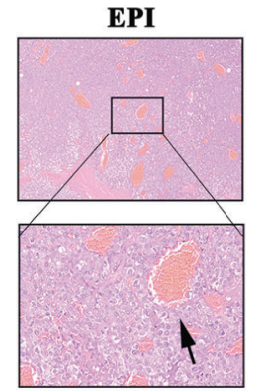
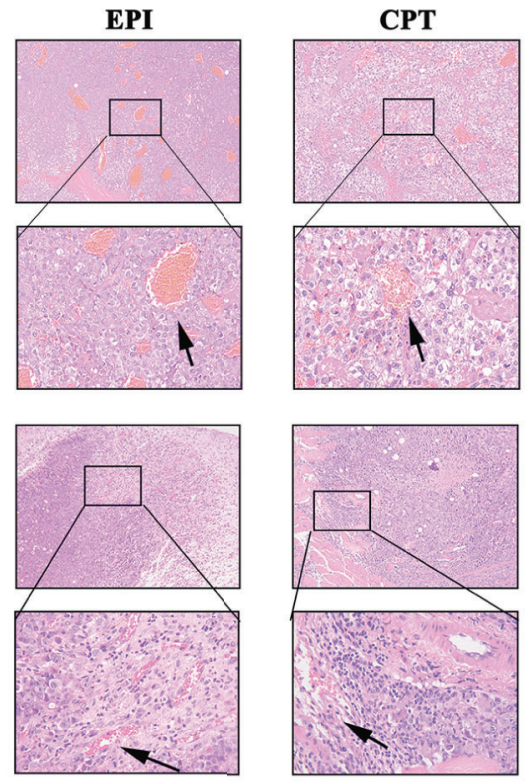

EPI
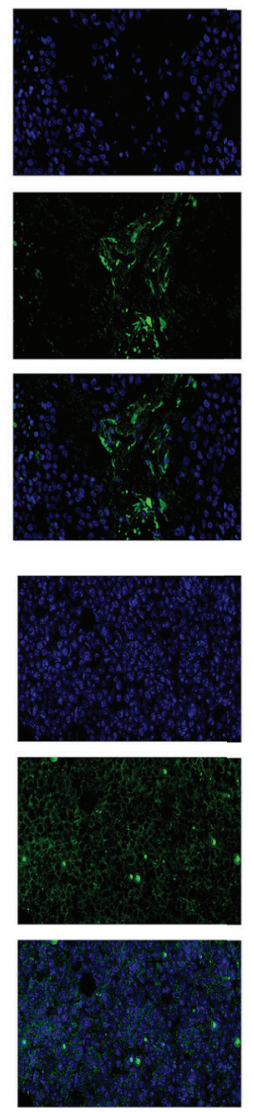

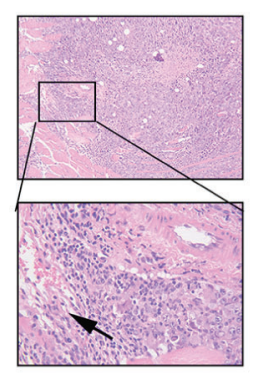

CPT
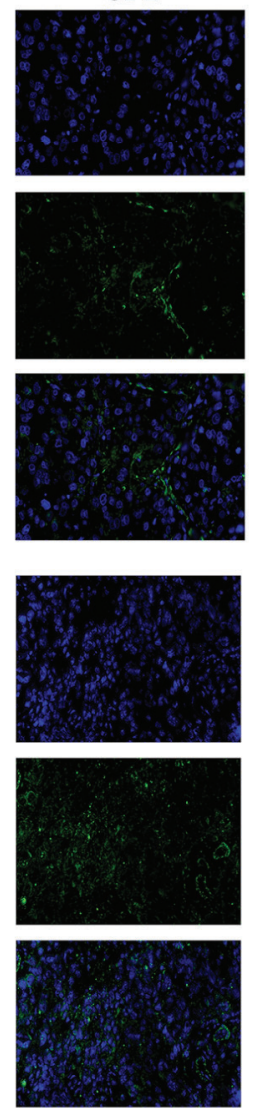


Combined


FIGURE 7 | CPT administration favors suppression of angiogenesis. (A) The H\&E staining of the Huh7 and H22 tumors at 100x and 400x magnification. The arrow showed the vessel inside the tumor. (B) The IF staining of VEGFR (green) in Huh7 and H22 tumor at 400x magnification. DAPI (blue) indicated the nucleus of the tumor cells. 
in HCC treatment. In this study, we aimed to prove that CPT do not increase the risk of HCC progression as the conventional chemotherapeutical drug, and to provide a new strategy for clinical control of HCC progression.

CPT was a chemotherapeutic drug used in clinics for a long time, and many studies suggested that CPT could inhibit the expression of $\mathrm{Nrf} 2(45,46)$. In our study, CPT was also proved to effectively inhibit ROS level and Nrf2 expression, while EPI could increase ROS level and induce high Nrf2 expression. Additionally, co-administration of CPT could suppress ROS generation and Nrf2 expression induced by EPI.

Nrf2 participate in cell proliferation by various pathways. Nrf2 knockout cells proliferated more slowly than wild-type cells (47-49). Over-expression of Nrf2 could modulate mRNA translation to promote tumor cell proliferation (50). Fan reported that Nrf2 promoted the proliferation of glioma cells through specifically adjusting ROS level and inducing resistance to ferroptosis (51). Our results indicated that EPI, CPT, and combination of EPI and CPT inhibited cell proliferation and tumor growth of HCC. However, EPI treatment induced Nrf2 expression and inhibited the proliferation of Huh7 cells as well as the tumor growth of Huh7 and H22. It might be due to that EPI could induce other inhibition patterns of cell growth, such as pro-apoptosis, G2/M arrest by CDK1 down-regulation, as well as the limitation of the nutrition supply towards cancer cells (5254). After down-regulating the EPI-induced Nrf2 by CPT, the proliferation and tumor growth of HCC were obviously decreased. All these strongly suggested that down-regulation of Nrf2 by CPT favored the inhibition of HCC growth.

EMT was the major biological process for tumor cell migration and invasion (55). In this process, cancer cells would lose connection with the basement membrane and get a capability of migration and invasion, following increasing degradation of extracellular matrix (ECM) (56). The core regulatory of EMT promoting transcription factors including E-cadherin, $\mathrm{N}$ cadherin, Twist and Snail participated in this process (57). Downregulation of E-cadherin cannot maintain normal epithelial cell morphology, resulting in the destroyed adhesion system and then inducing the tumor from non-infiltration to infiltration. Transcription factor Snail and Twist could directly or indirectly inhibit the activity of E-cadherin to promote EMT (58). N-cadherin played an important role in neovascularization and adhesion between tumor cells and mesenchymal cells. In esophageal squamous cell carcinoma cells and human ovarian cancer cells, Nrf2 promoted EMT phenomenon by down-regulation of Ecadherin and up-regulation of $\mathrm{N}$-cadherin through some unclear mechanisms $(31,59,60)$. Matrix metalloproteinase, such as MMP9, was required in the EMT process of cancer cells via degrading the cellular adhesion $(61,62)$. In Huh7 knockdown cells, the EMT process was inhibited. Although EPI could inhibit HCC growth, it did not suppress the EMT process. After Nrf2 down-regulation by CPT, the EMT process was also inhibited. These results demonstrated that Nrf2 down-regulation favored inhibition of the EMT process.

It was also reported that some cancer cells with strong metastatic capacity exhibited high Nrf2 expression (63).
Therefore, the wound healing, Transwell assays, and lung metastasis were performed to detect the invasion and metastasis ability of HCC after treatment with CPT. In vitro and in vivo studies demonstrated that EPI could inhibit invasion and metastasis in a certain level. This may be due to the inhibition of cell proliferation by EPI, resulting in slower invasion and metastasis. After inhibition of the Nrf2 expression by $\mathrm{CPT}$, the cell invasion and metastasis were suppressed. Meanwhile, our previous study indicated Nrf2 knockdown Huh7 cells had slower invasion and metastasis. These results revealed that Nrf2 down-regulation by CPT benefited for the suppression of invasion and metastasis.

The high metabolism of tumor in the growth process could result in a hypoxic micro-environment in the interior tumor. At this stage, the tumor could activate the growth factor such as VEGF and induce vasculature generation (64). Then VEGF activated VEGFR and promoted endothelial cell proliferation as well as tubule formation (65). In some xenograft models, knockdown of Nrf2 could reduce vasculature formation $(66,67)$. In HCC tumors, vascular quantity in different groups was found in the order: control group >, EPI group >, CPT group >, combination group. The difference of tumor volume and weight in different groups may be due to the different degrees of vascularization. In addition, there was difference in sensitivity to CPT between Huh 7 tumor and $\mathrm{H} 22$ tumor, probably due to the difference of angiogenesis. Furthermore, CPT treatment could also inhibit the expression of VEGFR in the tumor. All these illustrated that CPT could suppress Nrf2 and inhibit angiogenesis of HCC.

Although Nrf2 inhibition by CPT could suppress the progress of HCC, several limitations of the present study should be considered. The binding site of CPT on Nrf2. It would be interesting to explore the mechanism of Nrf2 inhibition.

\section{CONCLUSION}

In this study, CPT could inhibit the up-regulation of ROS and Nrf2 expression which were induced by EPI treatment. After down-regulation of Nrf2, Huh7 and H22 cells exhibited slow growth, weak invasion and metastasis, together with decreased angiogenesis. Therefore, Nrf2 may be a potential target for prediction of HCC metastasis.

\section{DATA AVAILABILITY STATEMENT}

The original contributions presented in the study are included in the article/supplementary material. Further inquiries can be directed to the corresponding authors.

\section{ETHICS STATEMENT}

All animal experiments were performed in agreement with the ARRIVE guidelines. The protocol was approved by the Animal 
Care and Use Committee of Shandong University with the corresponding ethical approval code (LL-201602040, 2016-2022).

\section{AUTHOR CONTRIBUTIONS}

FC and QL designed the studies. QL and SZ carried out the study, including data collection and data analysis. FM, HW and LS performed data analysis. QL wrote the original draft. SZ and FG edited the manuscript. GL and FC supervised. All authors contributed to the article and approved the submitted version.

\section{REFERENCES}

1. Heimbach JK, Kulik LM, Finn RS, Sirlin CB, Abecassis MM, Roberts LR, et al. AASLD Guidelines for the Treatment of Hepatocellular Carcinoma. Hepatology (2018) 67(1):358-80. doi: 10.1002/hep.29086

2. Yang JD, Hainaut P, Gores GJ, Amadou A, Plymoth A, Roberts LR. A Global View of Hepatocellular Carcinoma: Trends, Risk, Prevention and Management. Nat Rev Gastroenterol Hepatol (2019) 16(10):589-604. doi: 10.1038/s41575-019-0186-y

3. El-Serag HB, Rudolph KL. Hepatocellular Carcinoma: Epidemiology and Molecular Carcinogenesis. Gastroenterology (2007) 132(7):2557-76. doi: 10.1053/j.gastro.2007.04.061

4. Poon RT, Fan ST, Lo CM, Liu CL, Wong J. Intrahepatic Recurrence After Curative Resection of Hepatocellular Carcinoma: Long-Term Results of Treatment and Prognostic Factors. Ann Surg (1999) 229(2):216-22. doi: 10.1097/00000658-199902000-00009

5. Ahmad ST, Arjumand W, Nafees S, Seth A, Ali N, Rashid S, et al. Hesperidin Alleviates Acetaminophen Induced Toxicity in Wistar Rats by Abrogation of Oxidative Stress, Apoptosis and Inflammation. Toxicol Lett (2012) 208 (2):149-61. doi: 10.1016/j.toxlet.2011.10.023

6. Yamamoto M, Kensler TW, Motohashi H. The KEAP1-NRF2 System: A Thiol-Based Sensor-Effector Apparatus for Maintaining Redox Homeostasis. Physiol Rev (2018) 98(3):1169-203. doi: 10.1152/physrev.00023.2017

7. Bellezza I, Giambanco I, Minelli A, Donato R. Nrf2-Keap1 Signaling in Oxidative and Reductive Stress. Biochim Biophys Acta Mol Cell Res (2018) 1865(5):721-33. doi: 10.1016/j.bbamcr.2018.02.010

8. DeNicola GM, Karreth FA, Humpton TJ, Gopinathan A, Wei C, Frese K, et al. Oncogene-Induced Nrf2 Transcription Promotes ROS Detoxification and Tumorigenesis. Nature (2011) 475(7354):106-9. doi: 10.1038/ nature10189

9. Ma Q, He X. Molecular Basis of Electrophilic and Oxidative Defense: Promises and Perils of Nrf2. Pharmacol Rev (2012) 64(4):1055-81. doi: 10.1124/pr.110.004333

10. Itoh K, Mimura J, Yamamoto M. Discovery of the Negative Regulator of Nrf2, Keap1: A Historical Overview. Antioxid Redox Signal (2010) 13(11):1665-78. doi: 10.1089 /ars.2010.3222

11. Nguyen T, Nioi P, Pickett CB. The Nrf2-Antioxidant Response Element Signaling Pathway and its Activation by Oxidative Stress. J Biol Chem (2009) 284(20):13291-5. doi: 10.1074/jbc.R900010200

12. Li W, Kong AN. Molecular Mechanisms of Nrf2-mediated Antioxidant Response. Mol Carcinog (2009) 48(2):91-104. doi: 10.1002/mc.20465

13. Long M, Rojo de la Vega M, Wen Q, Bharara M, Jiang T, Zhang R, et al. An Essential Role of NRF2 in Diabetic Wound Healing. Diabetes (2016) 65 (3):780-93. doi: $10.2337 / \mathrm{db} 15-0564$

14. Zhang L, Wang N, Zhou S, Ye W, Jing G, Zhang M. Propofol Induces Proliferation and Invasion of Gallbladder Cancer Cells Through Activation of Nrf2. J Exp Clin Cancer Res (2012) 31(1):66. doi: 10.1186/1756-9966-31-66

15. Dudjak LA. Cancer Metastasis. Semin Oncol Nurs (1992) 8(1):40-50. doi: 10.1016/0749-2081(92)90007-p

16. Rojo de la Vega M, Chapman E, Zhang DD. NRF2 and the Hallmarks of Cancer. Cancer Cell (2018) 34(1):21-43. doi: 10.1016/j.ccell.2018.03.022

\section{FUNDING}

This study was funded by the Nature Science Foundation of China (grant no. 81803008 to FC) and the Natural Science Foundation of Shandong Province (grant no. ZR2019BH041 to FC).

\section{ACKNOWLEDGMENTS}

We thank Translational Medicine Core Facility of Shandong University for consultation and instrument availability that supported this work.

17. Díaz-López A, Díaz-Martín J, Moreno-Bueno G, Cuevas EP, Santos V, Olmeda D, et al. Zeb1 and Snaill Engage miR-200f Transcriptional and Epigenetic Regulation During EMT. Int J Cancer (2015) 136(4):E62-73. doi: 10.1002/ijc.29177

18. Mittal V. Epithelial Mesenchymal Transition in Tumor Metastasis. Annu Rev Pathol (2018) 13:395-412. doi: 10.1146/annurev-pathol-020117-043854

19. Scheau C, Badarau IA, Costache R, Caruntu C, Mihai GL, Didilescu AC, et al. The Role of Matrix Metalloproteinases in the Epithelial-Mesenchymal Transition of Hepatocellular Carcinoma. Anal Cell Pathol (Amst) (2019) 2019:9423907. doi: 10.1155/2019/9423907

20. Shin JH, Kim KM, Jeong JU, Shin JM, Kang JH, Bang K, et al. Nrf2-Heme Oxygenase-1 Attenuates High-Glucose-Induced Epithelial-to-Mesenchymal Transition of Renal Tubule Cells by Inhibiting Ros-Mediated Pi3k/Akt/Gsk$3 \beta$ Signaling. J Diabetes Res (2019) 2019:2510105. doi: 10.1155/2019/2510105

21. Binet F, Sapieha P. Er Stress and Angiogenesis. Cell Metab (2015) 22(4):56075. doi: 10.1016/j.cmet.2015.07.010

22. Guo Z, Mo Z. Keap1-Nrf2 Signaling Pathway in Angiogenesis and Vascular Diseases. J Tissue Eng Regener Med (2020) 14(6):869-83. doi: 10.1002/ term. 3053

23. Ji XJ, Chen SH, Zhu L, Pan H, Zhou Y, Li W, et al. Knockdown of NFE2-Related Factor 2 Inhibits the Proliferation and Growth of U251MG Human Glioma Cells in a Mouse Xenograft Model. Oncol Rep (2013) 30 (1):157-64. doi: 10.3892/or.2013.2476

24. Melincovici CS, Boşca AB, Şuşman S, Mărginean M, Mihu C, Istrate M, et al. Vascular Endothelial Growth Factor (VEGF) - Key Factor in Normal and Pathological Angiogenesis. Rom J Morphol Embryol (2018) 59(2):455-67.

25. Carmeliet P. VEGF as a Key Mediator of Angiogenesis in Cancer. Oncology (2005) 69 Suppl 3:4-10. doi: 10.1159/000088478

26. Chen F, Wang H, Zhu J, Zhao R, Xue P, Zhang Q, et al. Camptothecin Suppresses NRF2-ARE Activity and Sensitises Hepatocellular Carcinoma Cells to Anticancer Drugs. Br J Cancer (2017) 117(10):1495-506. doi: 10.1038/bjc.2017.317

27. Chang L, Huo B, Lv Y, Wang Y, Liu W. Ginsenoside Rg3 Enhances the Inhibitory Effects of Chemotherapy on Esophageal Squamous Cell Carcinoma in Mice. Mol Clin Oncol (2014) 2(6):1043-6. doi: 10.3892/mco.2014.355

28. Sosa V, Moliné T, Somoza R, Paciucci R, Kondoh H, ME LL. Oxidative Stress and Cancer: An Overview. Ageing Res Rev (2013) 12(1):376-90. doi: 10.1016/ j.arr.2012.10.004

29. Haorah J, Ramirez SH, Schall K, Smith D, Pandya R, Persidsky Y. Oxidative Stress Activates Protein Tyrosine Kinase and Matrix Metalloproteinases Leading to Blood-Brain Barrier Dysfunction. J Neurochem (2007) 101 (2):566-76. doi: 10.1111/j.1471-4159.2006.04393.x

30. Skinner HD, Zheng JZ, Fang J, Agani F, Jiang BH. Vascular Endothelial Growth Factor Transcriptional Activation Is Mediated by Hypoxia-Inducible Factor 1alpha, HDM2, and p70S6K1 in Response to Phosphatidylinositol 3Kinase/AKT Signaling. J Biol Chem (2004) 279(44):45643-51. doi: 10.1074/ jbc.M404097200

31. Arfmann-Knübel S, Struck B, Genrich G, Helm O, Sipos B, Sebens S, et al. The Crosstalk Between Nrf2 and TGF- $\beta 1$ in the Epithelial-Mesenchymal Transition of Pancreatic Duct Epithelial Cells. PloS One (2015) 10(7): e0132978. doi: 10.1371/journal.pone.0132978 
32. Fiskus W, Coothankandaswamy V, Chen J, Ma H, Ha K, Saenz DT, et al. Sirt2 Deacetylates and Inhibits the Peroxidase Activity of Peroxiredoxin- 1 to Sensitize Breast Cancer Cells to Oxidant Stress-Inducing Agents. Cancer Res (2016) 76(18):5467-78. doi: 10.1158/0008-5472.Can-16-0126

33. Cramer SL, Saha A, Liu J, Tadi S, Tiziani S, Yan W, et al. Systemic Depletion of L-cyst(e)ine With Cyst(E)Inase Increases Reactive Oxygen Species and Suppresses Tumor Growth. Nat Med (2017) 23(1):120-7. doi: 10.1038/ nm. 4232

34. Binet F, Sapieha P, Stress ER. And Angiogenesis. Cell Metab (2015) 22:560-75. doi: 10.1016/j.cmet.2015.07.010

35. Kim SK, Yang JW, Kim MR, Roh SH, Kim HG, Lee KY, et al. Increased Expression of Nrf2/ARE-Dependent Anti-Oxidant Proteins in TamoxifenResistant Breast Cancer Cells. Free Radic Biol Med (2008) 45:537-46. doi: 10.1016/j.freeradbiomed.2008.05.011

36. Zhu M, Fahl WE. Functional Characterization of Transcription Regulators That Interact With the Electrophile Response Element. Biochem Biophys Res Commun (2001) 289(1):212-9. doi: 10.1006/bbrc.2001.5944

37. Leinonen HM, Kansanen E, Pölönen P, Heinäniemi M, Levonen AL. Role of the Keap1-Nrf2 Pathway in Cancer. Adv Cancer Res (2014) 122:281-320. doi: 10.1016/b978-0-12-420117-0.00008-6

38. Baird L, Llères D, Swift S, Dinkova-Kostova AT. Regulatory Flexibility in the Nrf2-Mediated Stress Response Is Conferred by Conformational Cycling of the Keap1-Nrf2 Protein Complex. Proc Natl Acad Sci USA (2013) 110 (38):15259-64. doi: 10.1073/pnas.1305687110

39. Wild JM, Krützfeldt NO. Neocortical-Like Organization of Avian Auditory 'Cortex'. Commentary on Wang Y, Brzozowska-Prechtl a, Karten Hj (2010): Laminar and Columnar Auditory Cortex in Avian Brain. Proc Natl Acad Sci USA (2010) 107:12676-81. doi: 10.1159/000320215

40. Shelton P, Jaiswal AK. The Transcription Factor NF-E2-Related Factor 2 (Nrf2): A Protooncogene? FASEB J (2013) 27(2):414-23. doi: 10.1096/fj.12217257

41. Na HK, Surh YJ. Oncogenic Potential of Nrf2 and Its Principal Target Protein Heme Oxygenase-1. Free Radic Biol Med (2014) 67:353-65. doi: 10.1016/ j.freeradbiomed.2013.10.819

42. Xiang M, Namani A, Wu S, Wang X. Nrf2: Bane or Blessing in Cancer? J Cancer Res Clin Oncol (2014) 140(8):1251-9. doi: 10.1007/s00432-014-1627-1

43. Bailly C. Irinotecan: 25 Years of Cancer Treatment. Pharmacol Res (2019) 148:104398. doi: 10.1016/j.phrs.2019.104398

44. Chazin Ede L, Reis Rda R, Junior WT, Moor LF, Vasconcelos TR. An Overview on the Development of New Potentially Active Camptothecin Analogs Against Cancer. Mini Rev Med Chem (2014) 14:953-62. doi: 10.2174/1389557514666141029233037

45. Wu D, Shi W, Zhao J, Wei Z, Chen Z, Zhao D, et al. Assessment of the Chemotherapeutic Potential of a New Camptothecin Derivative, ZBH-1205. Arch Biochem Biophys (2016) 604:74-85. doi: 10.1016/j.abb.2016.06.007

46. Jayasooriya RG, Park SR, Choi YH, Hyun JW, Chang WY, Kim GY. Camptothecin Suppresses Expression of Matrix Metalloproteinase-9 and Vascular Endothelial Growth Factor in DU145 Cells Through PI3K/Aktmediated Inhibition of NF- $\mathrm{kb}$ Activity and Nrf2-Dependent Induction of HO-1 Expression. Environ Toxicol Pharmacol (2015) 39(3):1189-98. doi: 10.1016/j.etap.2015.04.011

47. Zhang M, Zhang C, Zhang L, Yang Q, Zhou S, Wen Q, et al. Nrf2 is a Potential Prognostic Marker and Promotes Proliferation and Invasion in Human Hepatocellular Carcinoma. BMC Cancer (2015) 15:531. doi: 10.1186/ s12885-015-1541-1

48. Lister A, Nedjadi T, Kitteringham NR, Campbell F, Costello E, Lloyd B, et al. Nrf2 Is Overexpressed in Pancreatic Cancer: Implications for Cell Proliferation and Therapy. Mol Cancer (2011) 10:37. doi: 10.1186/14764598-10-37

49. Murakami S, Motohashi H. Roles of Nrf2 in Cell Proliferation and Differentiation. Free Radic Biol Med (2015) 88(Pt B):168-78. doi: 10.1016/ j.freeradbiomed.2015.06.030

50. Chio IIC, Jafarnejad SM, Ponz-Sarvise M, Park Y, Rivera K, Palm W, et al. Nrf2 Promotes Tumor Maintenance by Modulating mRNA Translation in Pancreatic Cancer. Cell (2016) 166(4):963-76. doi: 10.1016/j.cell.2016.06.056

51. Fan Z, Wirth AK, Chen D, Wruck CJ, Rauh M, Buchfelder M, et al. Nrf2Keap1 Pathway Promotes Cell Proliferation and Diminishes Ferroptosis. Oncogenesis (2017) 6(8):e371. doi: 10.1038/oncsis.2017.65
52. Huang TC, Chiu PR, Chang WT, Hsieh BS, Huang YC, Cheng HL, et al. Epirubicin Induces Apoptosis in Osteoblasts Through Death-Receptor and Mitochondrial Pathways. Apoptosis (2018) 23(3-4):226-36. doi: 10.1007/ s10495-018-1450-2

53. Zhang X, Pan Y, Fu H, Zhang J. Nucleolar and Spindle Associated Protein 1 (Nusap1) Inhibits Cell Proliferation and Enhances Susceptibility to Epirubicin in Invasive Breast Cancer Cells by Regulating Cyclin D Kinase (CDK1) and DLGAP5 Expression. Med Sci Monitor (2018) 24:8553-64. doi: 10.12659/ MSM.910364

54. Kong L, Cai FY, Yao XM, Jing M, Fu M, Liu JJ, et al. RPV-Modified Epirubicin and Dioscin Co-Delivery Liposomes Suppress Non-Small Cell Lung Cancer Growth by Limiting Nutrition Supply. Cancer Sci (2020) 111(2):621-36. doi: $10.1111 /$ cas. 14256

55. Suarez-Carmona M, Lesage J, Cataldo D, Gilles C. EMT and Inflammation: Inseparable Actors of Cancer Progression. Mol Oncol (2017) 11(7):805-23. doi: 10.1002/1878-0261.12095

56. Saitoh M. Involvement of Partial EMT in Cancer Progression. J Biochem (2018) 164(4):257-64. doi: 10.1093/jb/mvy047

57. Zhou P, Li B, Liu F, Zhang M, Wang Q, Liu Y, et al. The Epithelial to Mesenchymal Transition (EMT) and Cancer Stem Cells: Implication for Treatment Resistance in Pancreatic Cancer. Mol Cancer (2017) 16(1):52. doi: 10.1186/s12943-017-0624-9

58. Zhu J, Zheng Y, Zhang H, Liu Y, Sun H, Zhang P. Galectin-1 Induces Metastasis and Epithelial-Mesenchymal Transition (EMT) in Human Ovarian Cancer Cells Via Activation of the MAPK Jnk/p38 Signalling Pathway. Am J Transl Res (2019) 11(6):3862-78.

59. Wakabayashi N, Shin S, Slocum SL, Agoston ES, Wakabayashi J, Kwak MK, et al. Regulation of Notch1 Signaling by Nrf2: Implications for Tissue Regeneration. Sci Signal (2010) 3(130):ra52. doi: 10.1126/scisignal.2000762

60. Shen H, Yang Y, Xia S, Rao B, Zhang J, Wang J. Blockage of Nrf2 Suppresses the Migration and Invasion of Esophageal Squamous Cell Carcinoma Cells in Hypoxic Microenvironment. Dis Esophagus (2014) 27(7):685-92. doi: 10.1111/ dote. 12124

61. Ling L, Chen L, Zhang C, Gui S, Zhao H, Li Z. High Glucose Induces Podocyte Epithelial-to-Mesenchymal Transition by Demethylation-Mediated Enhancement of MMP9 Expression. Mol Med Rep (2018) 17(4):5642-51. doi: $10.3892 / \mathrm{mmr} .2018 .8554$

62. Kessenbrock K, Plaks V, Werb Z. Matrix Metalloproteinases: Regulators of the Tumor Microenvironment. Cell (2010) 141(1):52-67. doi: 10.1016/j.cell. 2010.03.015

63. Shibata T, Saito S, Kokubu A, Suzuki T, Yamamoto M, Hirohashi S. Global Downstream Pathway Analysis Reveals a Dependence of Oncogenic NFE2-related Factor 2 Mutation on the mTOR Growth Signaling Pathway Cancer Res (2010) 70(22):9095-105. doi: 10.1158/0008-5472.Can-10-0384

64. Muz B, de la Puente P, Azab F, Azab AK. The Role of Hypoxia in Cancer Progression, Angiogenesis, Metastasis, and Resistance to Therapy. Hypoxia (Auckl) (2015) 3:83-92. doi: 10.2147/hp.S93413

65. Ma Q, Reiter RJ, Chen Y. Role of Melatonin in Controlling Angiogenesis Under Physiological and Pathological Conditions. Angiogenesis (2020) 23 (2):91-104. doi: 10.1007/s10456-019-09689-7

66. Kim TH, Hur EG, Kang SJ, Kim JA, Thapa D, Lee YM, et al. NRF2 Blockade Suppresses Colon Tumor Angiogenesis by Inhibiting Hypoxia-Induced Activation of HIF-1 $\alpha$. Cancer Res (2011) 71(6):2260-75. doi: 10.1158/0008-5472.Can-10-3007

67. Ji X, Wang H, Zhu J, Zhu L, Pan H, Li W, et al. Knockdown of Nrf2 Suppresses Glioblastoma Angiogenesis by Inhibiting Hypoxia-Induced Activation of HIF-1 $\alpha$. Int J Cancer (2014) 135(3):574-84. doi: 10.1002/ijc.28699

Conflict of Interest: The authors declare that the research was conducted in the absence of any commercial or financial relationships that could be construed as a potential conflict of interest.

Copyright () $2021 \mathrm{Liu}$, Zhao, Meng, Wang, Sun, Li, Gao and Chen. This is an openaccess article distributed under the terms of the Creative Commons Attribution License (CC BY). The use, distribution or reproduction in other forums is permitted, provided the original author(s) and the copyright owner(s) are credited and that the original publication in this journal is cited, in accordance with accepted academic practice. No use, distribution or reproduction is permitted which does not comply with these terms. 